\title{
Corneal Gene Therapy in Veterinary Medicine: A Review
}

\author{
Ann P. Bosiack ${ }^{1,2}$, Elizabeth A. Giuliano ${ }^{2}$ and Rajiv R. Mohan ${ }^{1,2,3 *}$
}

${ }^{1}$ Harry S. Truman Veterans Memorial Hospital, Columbia, Missouri, USA

${ }^{2}$ College of Veterinary Medicine, University of Missouri, Columbia, Missouri, USA

${ }^{3}$ Mason Eye Institute, School of Medicine, University of Missouri, Columbia, Missouri, USA

\begin{abstract}
The cornea is an ideal target for gene therapy due to its accessibility, immune-privileged nature, and ability to perform frequent non-invasive assessment. Gene therapy has been studied in animal models of ocular corneal graft rejection, neovascularization, wound healing, fibrosis, macular degeneration, optic neuropathy, and retinal degeneration. Medical research has widely used animal models in the pursuit of improved therapeutic strategies intended to aid people. In this review we summarize the vectors currently used in ocular gene therapy and the potential applications of emerging new strategies for use in veterinary medicine.
\end{abstract}

Keywords: Cornea; Gene therapy; Canine; Equine; Veterinary

\section{Introduction}

Almost all advances in ocular and vision research require the testing of new therapeutic strategies in animal models prior to pilot use in clinical trials. In vitro studies are commonly used prior to animal models in an effort to establish proof of principle and in some cases initial drug doses. Animal models are then needed to determine efficacy and establish toxicity levels associated with novel therapies. Although animal research is essential for furthering our understanding of vision and the treatment and prevention of ophthalmic disease in people, scientific advancement brought about through the use of animal testing is often slow to be adopted for use in the veterinary clinical patient compared to its use in physician ophthalmology.

Leber Congenital Amaurosis (LCA) is an inherited degenerative retinal disease that causes blindness in children. A majority of LCA cases are caused by mutations in the RPE65 gene. A naturally occurring RPE65 mutation in Briard dogs was found, similar to LCA in people [1]. A gene-knockout mouse model was produced, which in turn, greatly facilitated the development of gene-replacement strategies. Pioneer efforts in gene therapy for congenital LCA has demonstrated significant improvement of visual impairment in affected Briard dogs and is being used to help restore vision in children [2]. This wellknown scientific advancement serves to demonstrate the importance of animal models of retinal degeneration and the essential role they have played in the discovery of underling genetic defects, mechanism of disease, and development of therapeutic strategies. While rodents are commonly used, use of larger animal models (i.e. dog, cat, pig) has become increasingly attractive to assess the efficacy and safety of a variety of treatment modalities that are being considered for clinical trials in people. The successful establishment of a canine animal model for retinal diseases such as LCA is likely one important reason why retinal gene therapy has advanced faster than corneal gene therapy.

Comparative ophthalmic disease shared among many different species has long been recognized; however, recent international programmatical developments such as the One Health Initiative have fostered improved collaborations among health science professions, especially physicians and veterinarians. Similarities between the genomics and pathogenesis of many ocular diseases shared between people and animals has encouraged a convergence of knowledge between physician and veterinary ophthalmologists with significant potential to benefit the prevention, treatment, and diagnosis of many ophthalmic diseases. The cornea represents one of the most evolutionary conserved anatomic components across mammals with many shared pathological processes in various species. Corneal gene therapy is therefore an ideal target for collaborative biomedical research.

The potential therapeutic applications of gene therapy are vast. A major advantage of gene therapy over the use of conventional drugs is the prospect of curing disease rather than providing transient relief by suppression of disease symptoms. Replacing defective genes with functional genes through the use of gene therapy offers the prospect for long-term therapeutic benefits without repeated drug application. Successful vision restoration through the use of gene therapy in patients affected with LCA has demonstrated the ability of gene therapy to potentially cure ocular disease and prevent long-term blindness $[3,4]$. Further research in gene therapy is needed to develop treatments for other vision-impairing ocular diseases.

The cornea is an ideal target for gene therapy due to its accessibility, immune-privileged nature, and ability to perform frequent noninvasive assessment [5,6]. Gene therapy has been studied in animal models of ocular corneal graft rejection, neovascularization, wound healing, fibrosis, macular degeneration, optic neuropathy, and retinal degeneration [6-14]. The success of corneal gene therapy depends on the type of vector, the extent of therapeutic gene expression, and adverse immune responses [15].

\section{Vectors}

\section{Conventional vectors}

Several viral as well as non-viral vectors have been developed to transport genetic material into cells, each of which has advantages and limitations (Table 1) [6]. A detailed discussion of all currently used

*Corresponding author: Rajiv R. Mohan, Ph.D., Mason Eye Institute, EC-210, School of Medicine, University of Missouri, 1 Hospital Dr Columbia, MO 65212 Tel: (573) 884-1449; Fax: (573) 814-6551; E-mail: mohanr@health.missouri.edu

Received Dececmber 14, 2011; Accepted January 28, 2018; Published February 04, 2012

Citation: Bosiack AP, Giuliano EA, Mohan RR (2012) Corneal Gene Therapy in Veterinary Medicine: A Review. J Veterinar Sci Technol S8:001. doi:10.4172/21577579.S8-001

Copyright: (C) 2012 Bosiack AP, et al. This is an open-access article distributed under the terms of the Creative Commons Attribution License, which permits unrestricted use, distribution, and reproduction in any medium, provided the original author and source are credited. 


\begin{tabular}{|l|l|l|l|}
\hline Vector & Immunogenicity & $\begin{array}{l}\text { Long-term } \\
\text { expression }\end{array}$ & $\begin{array}{l}\text { Transduction of Dividing (D) } \\
\text { or Non-dividing (ND) cells }\end{array}$ \\
\hline AV & Moderate-severe & No & D \\
\hline AAV & No-mild & Yes & D and ND \\
\hline $\begin{array}{l}\text { Disabled } \\
\text { lentivirus }\end{array}$ & Mild-moderate & Yes & D and ND \\
\hline Retrovirus & Mild-moderate & No & D \\
\hline Naked Plasmid & No-mild & No & ND \\
\hline Lipids & No-moderate & No & ND \\
\hline
\end{tabular}

Table1: Characteristics of viral vectors used in corneal gene therapy.

viral and non-viral vectors in ocular gene therapy is beyond the scope of this review. Rather, this article will serve to review the most common vectors utilized for corneal gene therapy.

Several studies have assessed the efficacy of Adenovirus (AV) vectors for corneal gene therapy [6]. AV vectors have been shown to effectively deliver genes to the rodent cornea; however, they provide short-term transgene expression and stimulate moderate to severe inflammation [16,17]. Retroviral vectors can successfully deliver genes into the cornea but are not capable of transducing non-dividing cells [18]. Like adenovirus, retroviral vectors have also been shown to stimulate mild-to-severe inflammatory responses and have oncogenic potential due to their integration near proto-oncogenes, making them undesirable $[6,19]$. Lentiviral vectors appear to be safer than retroviral vectors due to their lower risk of tumor oncogenesis [19]. The origin of lentiviral vectors are the equine infectious anemia virus and the human immunodeficiency virus (HIV), thus safety remains a major concern. Attempts to improve safety of lentiviral vectors include creating vectors that lack the entire viral genome [20]. Disabled lentivirus vectors provide long-term transgene expression and are able to transduce slow/ non-dividing cells, making them better options for the transduction of corneal keratocytes and endothelial cells.

Adeno-Associated Virus (AAV) possesses several important properties that make it a highly successful vector for corneal gene therapy including its ability to transduce dividing and non-dividing cells, low pathogenicity, low immunogenicity, and long-term transgene expression [6]. Our previous studies found AAV to be a safe and efficient viral vector for transducing corneal cells and delivering therapeutic genes into the cornea of rabbits, mice, horses, and people [5,6,21-24]. Serotypes 1-9 of AAV are most commonly used for gene therapy [8]. Various studies have shown unique tropism and transduction efficacy of different AAV serotypes for specific tissues [8]. The finding of variable transduction efficiency and tissue tropism has led to comparative studies quantifying transduction efficiency of various AAV serotypes in corneal tissue. The efficacy of AAV2 and AAV5 to deliver genes into the corneal stroma of rabbits and rodents in vivo, as well as the ability of AAV6, AAV8, and AAV9 to deliver genes in mouse cornea in vivo and donor human cornea ex vivo has been established $[6,8]$. In a previous study, AAV5 was shown to have enhanced gene delivery when compared to AAV2 in the rabbit cornea [5].

Non-viral gene therapy is the introduction of therapeutic genes via plasmid DNA into target cells without the use of a virus. In general these techniques demonstrate low toxicity, immunogenicity, and pathogenicity, rendering these techniques safer than viral methods. However, they demonstrate low transduction efficiencies, which makes them less desirable. These techniques include microinjection, electroporation, sonoporation, gene gun, controlled corneal dehydration, laser, and chemical delivery methods. The reader is referred to a thorough review of these techniques in a recent publication by Mohan et al. [20].

\section{Contemporary vectors}

Tyrosine-mutant AAV: The AAV viral capsid plays a fundamental role in cellular tropism (i.e. binding and uptake) thus contributing to the efficiency of transgene expression. When the AAV vector is incorporated into the target cell it is vulnerable to normal cellular degradation pathways. By directly mutating the tyrosine residues on the viral capsid, the degradation mechanisms of the target cell are avoided, which leads to increased transduction [25]. When injected subretinally or intravitreally these tyrosine-mutant AAV vectors demonstrate several fold higher transgene delivery in target retinal cells than non-mutant AAV vectors [26]. The dose of tyrosine-mutant AAV vector required for transduction is also significantly lower than that of AAV which lessens the immune response [26]

Nanoparticles: Nanoparticles (NPs) offer an alternative to the use of viral vectors in gene therapy. NPs are particles that are 1-100 $\mathrm{nm}$ in size. There are several different forms of nanoparticles and they typically contain a segment of DNA or RNA that is compacted with a polycationic polymer [27]. Due to their small size, NPs can readily interact with molecules on the cell surface or inside cells. Unlike their viral vector counterparts, NPs do not introduce additional genes into target cells. They tend to be less immunogenic and cytotoxic than viral vectors [28]. Finally, NPs are able to incorporate numerous ligands such as DNA, antibodies, peptides, and probes and therefore present an array of therapeutic modalities. Pathways of cellular internalization of NPs include phagocytosis, macropinocytosis, clathrin- or caveolaemediated endocytosis, and other clathrin- and caveolae-independent endocytic pathways [27].

There has been successful vector gene transfer with the use of NPs in phase I/II clinical trials designed to treat cystic fibrosis [29]. Limited studies have investigated the use of NPs for ocular gene delivery $[27,30]$ Mohan et al. [31] recently evaluated the safety and toxicity of gene transfer technique using a 2-kDa polyethylenimine conjugated to gold nanoparticles (PEI2-GNPs) in the human cornea in vitro and in rabbit cornea in vivo [30]. PEI2-GNPs exhibited significant transgene delivery in human corneal fibroblasts and did not appear to alter cellular viability or phenotype. Rabbit in vivo studies revealed substantial gold uptake in the rabbit cornea with a slow clearance of GNPs over time. Our results to date suggest that PEI2-GNPs appear safe for use in the cornea and may have potential use for corneal gene therapy; however, further research examining the clearance of GNPs and their effects on the optical properties of the eye is needed [30].

\section{Species-specific Corneal Gene Therapy}

Minimal research focused on gene therapy for use in species other than people exists. As mentioned previously, animal models are regularly used prior to clinical trials in people. Preliminary basic science research that is performed in animal models is rarely aimed at specifically addressing those ocular diseases commonly encountered in veterinary ophthalmology. Our lab is the first to evaluate the use of corneal gene therapy in the horse and dog. Our findings are summarized below.

\section{Canine}

Recently, our lab investigated the safety and efficacy of adenoassociated vector serotype 5 (AAV5) for delivering enhanced green fluorescent protein (GFP) marker gene in canine corneal fibroblasts (CCFs) and canine corneal myofibroblasts (CCMs) [31]. Our in vitro study demonstrated no significant cell death or phenotypic change associated with AAV5 gene therapy on CCFs and CCMs. Furthermore 
the results of our study demonstrated that AAV5 is an effective vector for gene therapy in canine corneal fibroblasts and myofibroblasts in vitro, based on the successful transduction of GFP with AAV5 vector into CCFs and CCMs as determined via fluorescent microscopy (Figure $1)$.

To our knowledge this is the first study to investigate the efficacy of corneal gene therapy in dogs. Future studies are needed in order to establish the safety and immunogenicity of AAV5 in vivo. Specifically, investigation of the effects of varying viral concentrations, administration time, and gene delivery systems are warranted.

\section{Equine}

Our lab also demonstrated success in transfecting equine corneal stromal fibroblasts (ECFs) in vitro using a topical application of hybrid adeno-associated virus serotype 2/5 (AAV5) expressing the GFP marker gene [24]. The tested AAV5 vector did not cause any cellular phenotype changes or significant cell death and cell viability was maintained. This study demonstrated the successful transduction of a foreign gene, GFP, into ECFs with topically applied AAV5 via fluorescent microscopy. The noted transduction efficiency was $13.1 \%$. To our knowledge this was the first study to investigate the potential use of topical gene therapy for the equine cornea. As with our canine studies, further studies investigating the use of the AAV5 vector to effectively deliver therapeutic genes into the equine cornea in vivo are also needed.

\section{Potential Applications in Veterinary Medicine}

Corneal disease is a commonly encountered clinical problem in veterinary medicine. The cornea provides two thirds of the refractive power of the mammalian eye. Therefore corneal disease that results in disruption of corneal health (e.g. clarity or refractive properties) can lead to significant visual impairment. Unique properties of the cornea that enable this living tissue to be essentially optically clear render it susceptible to limited pathologic responses to injury and often opacification results. Some of the common corneal diseases encountered in veterinary medicine include keratitis (i.e. ulcerative, immune-mediated, keratoconjunctivitis sicca (KCS)), neoplasia, corneal dystrophy, dermoids, chemical burns, lacerations, and corneal degeneration, among others. We now present an overview of the potential applications of gene therapy for treatment of several common corneal diseases in veterinary medicine (Table 2).

\section{Corneal Transplantation}

In physician ophthalmology, by virtue of well-maintained and highly regulated eye-banks, viable full-thickness corneal transplants

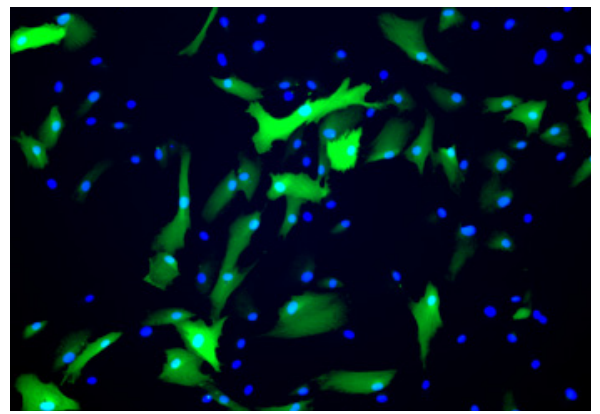

Figure 1: Representative image demonstrating AAV-delivered green fluorescent protein (GFP) staining in canine corneal fibroblasts (CCFs). DAPI staining is shown in blue and represents cell nuclei.

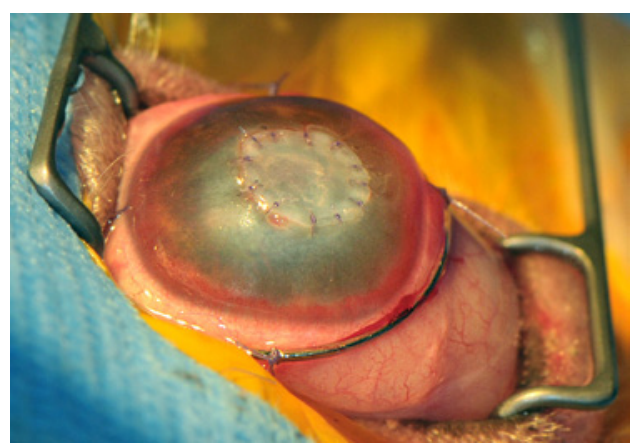

Figure 2: Intraoperative photograph of a corneal transplant being sutured into the axial cornea of a dog to repair a full thickness traumatic corneal perforation.

are commonly used. In veterinary medicine the use of fresh corneal transplants is limited for a number of reasons. First, harvesting and preservation requirements of donor corneal tissue is not feasible in the majority of veterinary practices [32]. Second, tissue typing and donorrecipient rejection concerns are not well understood. Third, medicallegal implication/permission of harvesting fresh, healthy donor cornea from a euthanized dog has not been established. Presently, veterinary ophthalmologists use frozen corneal transplants to provide tectonic support rather than optical clarity, as corneal endothelial cells do not survive the freezing process [32-34]. Common ocular conditions that may be treated with a previously frozen corneal transplant include descemetoceles, stromal abscesses, inflammatory keratitis with or without malacia, corneal perforation/iris prolapse (Figure2), and feline corneal sequestra $[32,34,35]$.

Corneal graft rejection involves the recognition of foreign antigens from the donor graft, which leads to an immune response by the host. Graft rejection is manifested by a loss of graft transparency after an initial time period of graft clarity (approximately 2 weeks in people and several days in horses) $[33,36]$. Corneal vascularization, inflammation, and/or infection in the host species prior to transplantation significantly increases the chance of corneal graft rejection or failure [36]. Human patients with these pre-existing corneal conditions are considered highrisk patients. Most veterinary patients that receive corneal transplants would therefore be considered high risk as almost all conditions in which corneal transplantation is indicated in veterinary medicine are characterized by these pre-existing conditions. The most important risk factor for graft rejection is host cornea vascularization [36]. In stark contrast to physician ophthalmology, corneal neovascularization is frequently a desired healing response since vascularization substantially improves the patient's ability to fight off corneal infection. Thus, while the vast majority of the corneal transplants performed in veterinary ophthalmology undergo "rejection" by physician standards, vascularization of the donor cornea is considered an optimal progression in wound healing in the majority of cases [32,33]

Prevention of corneal graft rejection currently is achieved by suppressing the host immune response. In humans, this is done with liberal use of systemic and topical corticosteroids as well as cyclosporine. In veterinary medicine the use of corticosteroids is contraindicated in the face of corneal infection, which is present in many of the patients that undergo corneal transplantation [37]. Therefore the development of an alternative therapy to corticosteroids, such as gene therapy, to prevent corneal graft rejection and the resultant long-term corneal fibrosis would be advantageous in veterinary medicine. 


\begin{tabular}{|c|c|c|c|c|c|}
\hline $\begin{array}{l}\text { Corneal pathologic } \\
\text { condition }\end{array}$ & Vectors tested & Genetic material & Model & Delivery route & $\begin{array}{l}\text { Effect on } \\
\text { pathology } \\
\text { resolution }\end{array}$ \\
\hline Graft rejection & AV, plasmids & $\begin{array}{l}\text { Cytotoxic T lymphocyte associated antigen 4, } \\
\text { Inducible T-cell co-stimulator, Interleukin (IL)-10 } \\
\text { antagonist, Interleukin-4 }\end{array}$ & $\begin{array}{l}\text { Mice, Rat, } \\
\text { Sheep, Ex vivo }\end{array}$ & IV, IP, Gene-gun & $+/-$ \\
\hline Wound healing & $\begin{array}{l}\text { AV, AAV, retrovirus, } \\
\text { Nanoparticles }\end{array}$ & $\begin{array}{l}\text { Decorin, Soluble type II TGF } \beta \text { receptor, Tissue } \\
\text { plasminogen activator }\end{array}$ & $\begin{array}{l}\text { Mice, Rat, } \\
\text { Rabbit, Ex vivo, } \\
\text { In vitro }\end{array}$ & $\begin{array}{l}\text { IM, Topical, Intrastromal, } \\
\text { Intracameral, } \\
\text { Electroporation }\end{array}$ &,$++/-,-$ \\
\hline Chemical burn & $\mathrm{AV}, \mathrm{AAV}$, plasmids & $\begin{array}{l}\text { Decorin, SMAD7, Peroxisome proliferator activated } \\
\text { receptor } \mathrm{Y}\end{array}$ & Mice, Rabbit & Topical &,$++/-$ \\
\hline Haze and Fibrosis & $\begin{array}{l}\text { AV, AAV, plasmids, } \\
\text { retrovirus. } \\
\text { Nanoparticles }\end{array}$ & $\begin{array}{l}\text { Decorin, SMAD7, Peroxisome proliferator activated } \\
\text { receptor y, Soluble type II TGF } \beta \text { receptor, BMP7, } \\
\text { Herpes simplex virus thymidine kinase, Dominant } \\
\text { negative cyclin G1 }\end{array}$ & $\begin{array}{l}\text { Rabbit, Ex vivo, } \\
\text { In vitro }\end{array}$ & Topical &,$++/-,-$ \\
\hline Neovascularization & $\begin{array}{l}\text { AV, AAV, plasmids, } \\
\text { lentivirus }\end{array}$ & $\begin{array}{l}\text { Decorin, Vascular endothelial growth factor elated } \\
\text { FLT-1, FLT23K, FLT24K, Endostsin, Kringle } 5 \\
\text { plasminogen, Angistatin, IL-2, IL-10 }\end{array}$ & $\begin{array}{l}\text { Mice, Rat, } \\
\text { Rabbit, Monkey, } \\
\text { In vitro }\end{array}$ & $\begin{array}{l}\text { IM, Topical, Intrastromal, } \\
\text { Intracameral, } \\
\text { Electroporation }\end{array}$ &,$++/-,-$ \\
\hline
\end{tabular}

Table2: Summary of corneal gene therapy research with potential application in veterinary ophthalmology.

The unique setting afforded by having an established tissue bank for corneal transplants is ideal for gene therapy, as donor cornea can easily be manipulated, ex vivo, prior to transplantation. Several gene therapy methods have been examined in an effort to improve graft survival by the delivery of therapeutic genes that modulate cellular apoptosis, angiogenesis, and wound healing [38]. One study investigated the delivery of an intracellular enzyme, indoleamine 2,3- dioxygenase (IDO), using a lentivirus vector in murine corneal endothelium [39]. Once activated by cytokines, IDO leads to the immunoregulatory catabolism of tryptophan. The reduction of tryptophan is thought to halt activated $\mathrm{T}$ cells in the cell cycle, which encourages immune tolerance of the transplanted cornea. This same research group also evaluated the effect of IDO transduction on donor corneas ex vivo prior to transplantation and found significant prolongation of corneal allograft survival compared to controls [40].

Another group found that the transfer of an anti-apoptotic gene, bcl-xL, using a lentivirus vector was effective at inhibiting apoptosis in the corneal endothelium in vitro in a rodent model, as well as significantly enhancing corneal graft survival in vivo [41]. Another application of gene therapy use for corneal transplantation involves the preservation of corneal endothelial cell density in corneal tissue that is stored at eye banks. One study demonstrated that the overexpression of transcription factor E2F2, using recombinant adenovirus ex vivo produced an increased endothelial cell count in rabbit and human corneas [42,43]. The E2F2 over-expression induced cell-cycle progression of corneal endothelial cells, which are normally amitotic, in the first week after transduction and without inducing significant apoptosis. This therapy has great potential for use in veterinary ophthalmology, since it is more practical to use corneas that have been preserved long-term. This type of gene therapy may prove especially beneficial in the treatment of corneal endotheliopathies.

\section{Corneal fibrosis/ modulation of corneal wound healing}

Corneal transparency and clarity rely on the special organization of the cornea's constituent components including corneal collagens and the extracellular matrix [6]. Corneal wound healing following injury and/or infection often results in fibrosis/scarring [44], which may cause significant visual impairment [45]. Much of the focus on the human side of corneal gene therapy for treatment of corneal fibrosis is geared towards reduction of photorefractive keratectomy-induced laser injury to the cornea. In veterinary ophthalmology corneal fibrosis (scar) is most commonly an outcome following complicated corneal ulceration and wound healing. As previously discussed, because vascularization is a desired component of the healing response in many veterinary cases that require corneal transplantation, perhaps the role of gene therapy would be better served to address the fibrosis that results from graft rejection.

Ulcerative keratitis is a significant clinical problem in veterinary ophthalmology [45]. Treatment of deep corneal ulcers typically demands both medical and surgical therapeutic strategies [46]. Surgical procedures utilized for the repair of deep corneal ulceration include conjunctival grafts, corneal grafts, corneo-conjunctival transposition, natural material transplants, and application of tissue adhesives [4750]. These procedures and their associated inflammatory response typically result in moderate to severe corneal scarring. Currently, no pharmacologic agents specifically aimed at reducing corneal fibrosis are routinely used in veterinary ophthalmology.

The transformation of quiescent keratocytes to corneal fibroblasts and myofibroblasts has been identified as the primary event in corneal wound healing that is responsible for fibrosis. While the production of myofibroblasts is a normal part of the complex process of corneal wound healing, the overproduction of myofibroblasts can lead to vision loss due to corneal scarring [51].

As previously mentioned our lab investigated the safety and efficacy of AAV5 for delivering gene therapy in canine corneal fibroblasts (CCFs) as a model of the pre-fibrotic state as well as in canine corneal myofibroblasts (CCMs), as a model of corneal fibrosis. Our results demonstrated that AAV5 is an effective vector for gene therapy in canine corneal fibroblasts and myofibroblasts in vitro. The transduction rate in CCFs was $42.8 \%$ CCFs and $28.0 \%$ in CCMs. The tested AAV5 vector showed significantly less transduction of CCMs compared to CCFs. This difference in transduction efficiency of AAV5 between the two cell types may suggest that higher doses of vector are required for delivering therapeutic genes into fibrotic tissue and it may signify the importance of therapeutic strategies aimed at initial prevention of corneal fibrosis versus treatment of established fibrosis. However, other potential causes of this noted transduction efficiency difference may be due to the specific cell tropism of the viral vector. Future studies are underway to investigate different AAV serotypes in order to determine if a particular serotype demonstrates specific tropism for canine corneal myofibroblasts.

Of the various cytokines that contribute to the development of corneal fibrosis following injury, TGF $\beta 1$ has been found to play a critical role by facilitating the transdifferentiation of corneal keratocytes to fibroblasts and myofibroblasts [44]. It has been shown that inhibition of corneal myofibroblast formation reduces corneal fibrosis and increases corneal transparency [52-55]. Therefore, it is 
thought that inhibiting TGF $\beta$ and/or its signal transduction may be a useful strategy to regulate uncontrolled corneal healing and to prevent or treat corneal scarring. Much research has been focused on gene therapy approaches to modulate TGF $\beta$ function and the subsequent development of corneal fibrosis.

Decorin, a small proteoglycan, which is a natural inhibitor of TGF $\beta$ has been successfully delivered to the cornea by the use of gene therapy. Mohan et al. [56] recently showed that decorin gene transfection inhibits TGF $\beta$-driven elevated expression of profibrogenic genes and transformation of corneal fibroblasts to myofibroblasts in human corneal fibroblast cultures. Our laboratory also demonstrated a significant inhibition of corneal scarring in vivo in the rabbit with the use of AAV5-mediated decorin gene therapy and did not detect any adverse effects at a time point of one-month following transduction [57]. This was the first study to establish the therapeutic potential of decorin gene therapy for treating corneal diseases. Currently, long-term studies are underway in order to assess whether the over-expression of decorin will cause any ocular complications or changes in corneal function or transparency [20].

The ability of gene therapy to prevent corneal scarring in experimental animals has been demonstrated in several previous studies as well. Seitz et al. [58] evaluated the use of retroviral vectormediated genetic transduction of rabbit keratocytes in vivo modulating keratocyte proliferation and decreasing corneal scarring. They employed the use of a suicide gene and pro-drug combination of the herpes simplex virus thymidine kinase (HSVtk) gene with ganciclovir. HSVtk triggers cell death in proliferating keratocytes by converting ganciclovir to a toxic metabolite. This combination gene therapy reduced corneal scarring 10 and 21 days post administration. Galiacy et al. [59] utilized an AAV vector expressing a fibril collagenase, matrix metalloproteinase 14 (MMP14), in a murine model of corneal scarring [59]. They observed that MMP14 gene delivery reduced corneal opacity and expression of several major genes involved in corneal scarring. These findings are encouraging with regards to new developments for the prevention and treatment of corneal fibrosis with direct application to the veterinary ophthalmic patient.

\section{Corneal dystrophies}

Corneal stromal dystrophy refers to a group of inherited corneal diseases that are typically bilateral, symmetric and slowly progressive, with absent inflammation [60]. They are caused by an accumulation of material such as lipid or cholesterol crystals in the cornea. There are several forms of corneal dystrophy, which vary in their expression, location within the cornea, and degree of vision loss. The dog is the most common nonhuman species that is affected by corneal dystrophy and the condition is rare in other species. This condition manifests as bilateral crystalline or white opacities in the central or paracentral cornea [61]. Specific breeds that are described in the literature to be affected by stromal dystrophies include the Shetland Sheepdog, Beagle, Siberian Husky, Cavalier King Charles Spaniel, Airedale Terrier and Rough Collie [62]. In people the resulting corneal opacity causes visual impairment. In dogs, stromal dystrophies infrequently lead to significantly appreciable functional vision loss. Nevertheless, complete vision loss secondary to corneal dystrophy has been reported in Airedale Terriers and Siberian Huskies [60]. Boston Terriers, Chihuahuas and Dachshunds are affected by corneal endothelial dystrophy, and the American Cocker Spaniel has been reported to develop a posterior polymorphous dystrophy [62]. Endothelial dystrophies (except the posterior polymorphous dystrophy in the American Cocker Spaniel) are characterized by progressive corneal edema, which can lead to vision loss, bullous keratopathy, and corneal ulcers [60].

Several genetic mutations in people with corneal dystrophies have been identified $[63,64]$. The pathogenesis and localization of many additional genes likely responsible for these corneal diseases have yet to be identified. A paucity of research in the realm of gene therapy for the treatment of corneal dystrophies exists for several reasons. There is a lack of animal models for most of the corneal dystrophies described in people. The few mouse lines that have been created to express corneal dystrophy genetic mutations do not exhibit similar clinical manifestations of these diseases as observed in people [65]. Additionally, the common use of corneal transplantation as a relatively effective treatment in people may imply that corneal dystrophies are less visually debilitating than other ocular diseases for which no treatment exists and as such, limited research funding may be available to study corneal dystrophies at this time. Specific gene localization and targeting is vital for the development of animal models of this category of corneal disease and for gene therapy treatment advances.

As is the case in physician ophthalmology, in veterinary ophthalmology there is a lack of research focused on treatment of corneal dystrophies. Corneal dystrophies generally do not respond to medical treatment; therefore, unless they cause an obvious loss of vision or have complications (e.g. corneal ulceration) they are often treated with benign neglect. Treatment of progressive corneal edema with endothelial dystrophy is palliative. When dogs develop recurrent ulcers as a complication of dystrophies or persistent bullous keratopathy secondary to endothelial dystrophy they may benefit from thermokeratoplasty or keratoleptynsis $[62,66]$. Definitive treatment includes a living (i.e. one with functional donor corneal endothelial cells) corneal transplant as previously described but is associated with relatively high failure rates in dogs. Presently, there are no treatment strategies utilizing gene therapy for corneal dystrophies in veterinary ophthalmology. The corneal tissue-selective gene therapy approaches that are currently under investigation may have potential for the treatment of corneal dystrophies in dogs.

\section{Other}

Mucopolysaccharidosis (MPS) is a group of lysosomal storage diseases characterized by the defective metabolism of glycosaminoglycans (GAG). Five types of MPS have been described in dogs (MPS I, II, III, VI, VII). While MPS is relatively rare in veterinary medicine, the use of dogs in research is not uncommon because they serve as a large animal model for human disease. Corneal pathology typically involves opacification of the cornea due to lysosomal storage in keratocytes [38]. Intravenous gene therapy in neonatal MPS dogs using a retroviral vector has been shown to prevent GAG accrual and resultant corneal clouding.[67,68] Corneal clouding in untreated MPS I dogs resulted in a blurry view of the fundus as well as a granular appearance of the cornea due to the lysosomal storage. A marked reduction in corneal clouding was shown with systemic gene therapy using a retroviral vector in neonatal MPS I dogs [67].

\section{Conclusions}

Animal models represent the corner stone of gene-therapy research. Many of the advancements made to date have been possible through the appropriate use of rodents, rabbits, dogs, cats, pigs, and non-human primates. Given the obvious comparative ophthalmic implications to many of the recent scientific discoveries in vision science, the potential for translational research to directly impact our veterinary ophthalmic 
Citation: Bosiack AP, Giuliano EA, Mohan RR (2012) Corneal Gene Therapy in Veterinary Medicine: A Review. J Veterinar Sci Technol S8:001. doi:10.4172/2157-7579.S8-001

Page 6 of 7

patients is exciting. Our laboratory's recent research in canine and equine corneas in vitro as well as significant progress and advancement in the field of corneal gene therapy in the last decade holds important promise for the improvement of long-term vision in our veterinary patients and thus, improvement of animal welfare.

\section{References}

1. Aguirre GD, Baldwin V, Pearce-Kelling S, Narfstrom K, Ray K, et al. (1998) Congenital stationary night blindness in the dog: common mutation in the RPE65 gene indicates founder effect. Mol Vis 4: 23.

2. Acland GM, Aguirre GD, Ray J, Zhang Q, Aleman TS, et al. (2001) Gene therapy restores vision in a canine model of childhood blindness. Nat Genet 28: 92-95.

3. Bainbridge JW, Ali RR (2008) Success in sight: The eyes have it! Ocular gene therapy trials for LCA look promising. Gene Ther 15: 1191-1192.

4. Maguire AM, Simonelli F, Pierce EA, Pugh EN Jr, Mingozzi F, et al. (2008) Safety and efficacy of gene transfer for Leber's congenital amaurosis. N Engl J Med 358: 2240-2248.

5. Mohan RR, Schultz GS, Hong JW, Wilson SE (2003) Gene transfer into rabbit keratocytes using AAV and lipid-mediated plasmid DNA vectors with a lamellar flap for stromal access. Exp Eye Res 76: 373-383.

6. Mohan RR, Sharma A, Netto MV, Sinha S, Wilson SE (2005) Gene therapy in the cornea. Prog Retin Eye Res 24: 537-559.

7. Saika S, Yamanaka O, Sumioka T, Miyamoto T, Miyazaki K, et al. (2008) Fibrotic disorders in the eye: targets of gene therapy. Prog Retin Eye Res 27: 177-196.

8. Sharma A, Ghosh A, Hansen ET, Newman JM, Mohan RR (2010) Transduction efficiency of AAV 2/6, 2/8 and 2/9 vectors for delivering genes in human corneal fibroblasts. Brain Res Bull 81: 273-278.

9. Behrens A, Gordon EM, Li L, Liu PX, Chen Z, et al. (2002) Retroviral gene therapy vectors for prevention of excimer laser-induced corneal haze. Invest Ophthalmol Vis Sci 43: 968-977.

10. Cheng HC, Yeh SI, Tsao YP, Kuo PC (2007) Subconjunctival injection of recombinant AAV-angiostatin ameliorates alkali burn induced corneal angiogenesis. Mol Vis 13: 2344-2352.

11. Klausner EA, Peer D, Chapman RL, Multack RF, Andurkar SV (2007) Cornea gene therapy. J Control Release 124: 107-133.

12. Parker DG, Brereton HM, Coster DJ, Williams KA (2009) The potential of vira vector-mediated gene transfer to prolong corneal allograft survival. Curr Gene Ther 9: 33-44.

13. Stieger K, Cronin T, Bennett J, Rolling F (2011) Adeno-associated virus mediated gene therapy for retinal degenerative diseases. Methods Mol Bio 807: 179-218.

14. Hellstrom M, Harvey AR (2011) Retinal ganglion cell gene therapy and visual system repair. Curr Gene Ther 11: 116-131.

15. Sharma A, Tovey JC, Ghosh A, Mohan RR (2010) AAV serotype influences gene transfer in corneal stroma in vivo. Exp Eye Res 91: 440-448.

16. Ritter T, Yang J, Dannowski H, Vogt K, Volk HD, et al. (2007) Effects of interleukin-12p40 gene transfer on rat corneal allograft survival. Transpl Immunol 18: 101-107.

17. Yu H, Wu J, Li H, Wang Z, Chen X, et al. (2007) Inhibition of corneal neovascularization by recombinant adenovirus-mediated sFlk-1 expression. Biochem Biophys Res Commun 361: 946-952.

18. Somia N, Verma IM (2000) Gene therapy: trials and tribulations. Nat Rev Genet 1: $91-99$

19. Montini E, Cesana D, Schmidt M, Sanvito F, Ponzoni M, et al. (2006) Hematopoietic stem cell gene transfer in a tumor-prone mouse model uncovers low genotoxicity of lentiviral vector integration. Nat Biotechnol 24: 687-696.

20. Mohan RR, Tovey JC, Sharma A, Tandon A (2011) Gene therapy in the cornea: 2005--present. Prog Retin Eye Res 31: 43-64.

21. Monahan PE, Samulski RJ (2000) Adeno-associated virus vectors for gene therapy: more pros than cons? Mol Med Today 6: 433-440
22. Monahan PE, Samulski RJ (2000) AAV vectors: is clinical success on the horizon? Gene Ther 7: 24-30.

23. Royo NC, Vandenberghe LH, Ma JY, Hauspurg A, Yu L, et al. (2008) Specific AAV serotypes stably transduce primary hippocampal and cortical cultures with high efficiency and low toxicity. Brain Res 1190: 15-22.

24. Buss DG, Giuliano E, Sharma A, Mohan RR (2010) Gene delivery in the equine cornea: a novel therapeutic strategy. Vet Ophthalmol 13: 301-306.

25. Zhong L, Li B, Jayandharan G, Mah CS, Govindasamy L, et al. (2008) Tyrosinephosphorylation of AAV2 vectors and its consequences on viral intracellular trafficking and transgene expression. Virology 381: 194-202.

26. Petrs-Silva H, Dinculescu A, Li Q, Min SH, Chiodo V, et al. (2009) High efficiency transduction of the mouse retina by tyrosine-mutant AAV serotype vectors. Mol Ther 17: 463-471.

27. Cai X, Conley S, Naash M (2008) Nanoparticle applications in ocular gene therapy. Vision Res 48: 319-324.

28. Farjo R, Skaggs J, Quiambao AB, Cooper MJ, Naash MI (2006) Efficient nonviral ocular gene transfer with compacted DNA nanoparticles. PloS One 1: e38.

29. Konstan MW, Davis PB, Wagener JS, Hilliard KA, Stern RC, et al. (2004) Compacted DNA nanoparticles administered to the nasal mucosa of cystic fibrosis subjects are safe and demonstrate partial to complete cystic fibrosis transmembrane regulator reconstitution. Hum Gene Ther 15: 1255-1269.

30. Sharma A, Tandon A, Tovey JC, Gupta R, Robertson JD, et al. (2011) Polyethylenimine-conjugated gold nanoparticles: Gene transfer potential and low toxicity in the cornea. Nanomedicine 7: 505-513.

31. Bosiack AP, Giuliano EA, Gupta R, Mohan RR (2011) Canine corneal fibroblast and myofibroblast transduction with AAV5. Vet Ophthalmol.

32. Hansen PA, Guandalini A (1999) A retrospective study of 30 cases of frozen lamellar corneal graft in dogs and cats. Vet Ophthalmol 2: 233-241.

33. Brooks DE, Plummer CE, Kallberg ME, Barrie KP, Ollivier FJ, et al. (2008) Corneal transplantation for inflammatory keratopathies in the horse: visual outcome in 206 cases (1993-2007). Vet Ophthalmol 11: 123-133.

34. Pena Gimenez MT, Farina IM (1998) Lamellar keratoplasty for the treatment of feline corneal sequestrum. Vet Ophthalmol 1: 163-161.

35. Brooks DE (2010) Targeted lamellar keratoplasty in the horse: a paradigm shift in equine corneal transplantation. Equine Vet J 37: 24-30.

36. Panda A, Vanathi M, Kumar A, Dash Y, Priya S (2007) Corneal graft rejection. Surv Ophthalmol 52: 375-396.

37. Denis HM (2004) Equine corneal surgery and transplantation. Vet Clin North Am Equine Pract 20: 361-380.

38. Williams KA, Coster DJ (2010) Gene therapy for diseases of the cornea - a review. Clin Experiment Ophthalmol 38: 93-103.

39. Beutelspacher SC, Tan PH, McClure MO, Larkin DF, Lechler RI, et al. (2006) Expression of indoleamine 2,3-dioxygenase (IDO) by endothelial cells: implications for the control of alloresponses. Am J Transplant 6: 1320-1330.

40. Beutelspacher SC, Pillai R, Watson MP, Tan PH, Tsang J, et al. (2006) Function of indoleamine 2,3-dioxygenase in corneal allograft rejection and prolongation of allograft survival by over-expression. Eur J Immunol 36: 690-700.

41. Barcia RN, Dana MR, Kazlauskas A (2007) Corneal graft rejection is accompanied by apoptosis of the endothelium and is prevented by gene therapy with bcl-xL. Am J Transplant 7: 2082-2089.

42. Joyce NC, Harris DL, Mc Alister JC, Ali RR, Larkin DF (2004) Effect of overexpressing the transcription factor E2F2 on cell cycle progression in rabbit corneal endothelial cells. Invest Ophthalmol Vis Sci 45: 1340-1348.

43. McAlister JC, Joyce NC, Harris DL, Ali RR, Larkin DF (2005) Induction of replication in human corneal endothelial cells by E2F2 transcription factor cDNA transfer. Invest Ophthalmol Vis Sci 46: 3597-3603.

44. Tandon A, Tovey JC, Sharma A, Gupta R, Mohan RR (2010) Role of transforming growth factor Beta in corneal function, biology and pathology. Curr Mol Med 10: 565-578.

45. Wilkie DA, Whittaker C (1997) Surgery of the cornea. Vet Clin North Am Small Anim Pract 27: 1067-1107.

46. Wichayacoop T, Briksawan P, Tuntivanich P, Yibchok-Anun S (2009) Anti- 
Citation: Bosiack AP, Giuliano EA, Mohan RR (2012) Corneal Gene Therapy in Veterinary Medicine: A Review. J Veterinar Sci Technol S8:001. doi:10.4172/2157-7579.S8-001

inflammatory effects of topical supernatant from human amniotic membrane cell culture on canine deep corneal ulcer after human amniotic membrane transplantation. Vet Ophthalmol 12: 28-35.

47. Barros PS, Safatle AM, Godoy CA, Souza MS, Barros LF, et al. (2005) Amniotic membrane transplantation for the reconstruction of the ocular surface in three cases. Vet Ophthalmol 8: 189-192.

48. Brightman AH, McLaughlin SA, Brogdon JD (1989) Autogenous lamellar corneal grafting in dogs. J Am Vet Med Assoc 195: 469-475.

49. Hansen PA, Guandalini A (1999) A retrospective study of 30 cases of frozen lamellar corneal graft in dogs and cats. Vet Ophthalmol 2: 233-241.

50. Vanore M, Chahory S, Payen G, Clerc B (2007) Surgical repair of deep melting ulcers with porcine small intestinal submucosa (SIS) graft in dogs and cats. Vet Ophthalmol 10: 93-99.

51. Jester JV, Huang J, Barry-Lane PA, Kao WW, Petroll WM, et al. (1999) Transforming growth factor(beta)-mediated corneal myofibroblast differentiation requires actin and fibronectin assembly. Invest Ophthalmol Vis Sci 40: 19591967.

52. Netto MV, Mohan RR, Ambrosio R Jr, Hutcheon AE, Zieske JD, et al. (2005) Wound healing in the cornea: a review of refractive surgery complications and new prospects for therapy. Cornea 24: 509-522.

53. Conrad GW, Funderburgh JL (1992) Eye development and the appearance and maintenance of corneal transparency. Trans Kans Acad Sci 95: 34-38.

54. Boote C, Dennis S, Newton RH, Puri H, Meek KM (2003) Collagen fibrils appear more closely packed in the prepupillary cornea: optical and biomechanical implications. Invest Ophthalmol Vis Sci 44: 2941-2948.

55. Maurice DM (1970) The transparency of the corneal stroma. Vision Res 10 107-108.

56. Mohan RR, Gupta R, Mehan MK, Cowden JW, Sinha S (2010) Decorin transfection suppresses profibrogenic genes and myofibroblast formation in human corneal fibroblasts. Exp Eye Res 91: 238-245.

57. Mohan RR, Tandon A, Sharma A, Cowden JW, Tovey JC (2011) Significant inhibition of corneal scarring in vivo with tissue-selective, targeted AAV5 decorin gene therapy. Invest Ophthalmol Vis Sci 52: 4833-4841.

58. Seitz B, Moreira L, Baktanian E, Sanchez D, Gray B, et al. (1998) Retrovira vector-mediated gene transfer into keratocytes in vitro and in vivo. Am J Ophthalmol 126: 630-639.

59. Galiacy SD, Fournie P, Massoudi D, Ancele E, Quintyn JC, et al. (2011) Matrix metalloproteinase 14 overexpression reduces corneal scarring. Gene Ther 18 $462-468$.

60. Cooley PL, Dice PF 2nd (1990) Corneal dystrophy in the dog and cat. Vet Clin North Am Small Anim Pract 20: 681-692.

61. Crispin SM (1988) Crystalline corneal dystrophy in the dog. Histochemical and ultrastructural study. Cornea 7: 149-161.

62. Gilger BC, Bentley E, Ollivier FJ (2007) Diseases and Surgery of the Canine Cornea and Sclera. In: Vet Ophthalmol. (ed. Gelatt KN). (4th edn), Blackwell Publishing, Ames, lowa, 690-752.

63. Kim JH, Ko JM, Lee I, Kim JY, Kim MJ, et al. (2011) A novel mutation of the decorin gene identified in a korean family with congenital hereditary stromal dystrophy. Cornea 30: 1473-1477.

64. Aldave AJ (2011) The genetics of the corneal dystrophies. Dev Ophthalmo 48: 51-66.

65. Weiss JS (2010) Corneal dystrophies: molecular genetics to therapeutic intervention--Fifth ARVO/Pfizer Ophthalmics Research Institute Conference. Invest Ophthalmol Vis Sci 51: 5391-5402.

66. Maguire LJ, Shearer DR (1991) A simple method of conjunctival dissection for Gunderson flaps. Arch Ophthalmol 109: 1168-1169.

67. Traas AM, Wang P, Ma X, Tittiger M, Schaller L, et al. (2007) Correction of clinical manifestations of canine mucopolysaccharidosis I with neonatal retroviral vector gene therapy. Mol Ther 15: 1423-1431.

68. Wang B, O'Malley TM, Xu L, Vite C, Wang P, et al. (2006) Expression in blood cells may contribute to biochemical and pathological improvements afte neonatal intravenous gene therapy for mucopolysaccharidosis VII in dogs. Mol Genet Metab 87: 8-21.
This article was originally published in a special issue, Veterinary Gene Therapy handled by Editor(s). Dr. J Schumann, University of Leipzig, Germany 